\title{
Carbon Dot/Naphthalimide Based Ratiometric Fluorescence Biosensor for Hyaluronidase Detection
}

\author{
Pushap Raj ${ }^{1}$, Seon-yeong Lee ${ }^{2}$ and Tae Yoon Lee ${ }^{1,2, *}$ \\ 1 Department of Convergence System Engineering and Department of Biomedical Engineering, \\ Chungnam National University, 99 Daehak-ro, Yuseong-gu, Daejeon 34134, Korea; pushap143@cnu.ac.kr \\ 2 Department of Technology Education, Chungnam National University, 99 Daehak-ro, Yuseong-gu, \\ Daejeon 34134, Korea; t.sylee29@gmail.com \\ * Correspondence: taeyoon.lee@cnu.ac.kr
}

Citation: Raj, P.; Lee, S.-y.; Lee, T.Y Carbon Dot/Naphthalimide Based Ratiometric Fluorescence Biosensor for Hyaluronidase Detection. Materials 2021, 14, 1313. https:// doi.org/10.3390/ma14051313

Academic Editor: Erik Reimhult

Received: 27 January 2021

Accepted: 7 March 2021

Published: 9 March 2021

Publisher's Note: MDPI stays neutral with regard to jurisdictional claims in published maps and institutional affiliations.

Copyright: (C) 2021 by the authors. Licensee MDPI, Basel, Switzerland. This article is an open access article distributed under the terms and conditions of the Creative Commons Attribution (CC BY) license (https:/ / creativecommons.org/licenses/by/ $4.0 /)$.

\begin{abstract}
Bladder cancer is the leading cause of death in patients with genitourinary cancer. An elevated level of hyaluronidase (HAase) was found in bladder cancer, which acts as an important biomarker for the early diagnosis of bladder cancer. Hence, there is a need to develop a simple enzymatic assay for the early recognition of HAase. Herein, we report a simple, sensitive, and ratiometric fluorescence assay for HAase detection under physiological conditions. The fluorescence assay was constructed by the adsorption of cationic carbon dots and positively charged naphthalimide on negatively charged hyaluronic acid and the development of a Förster resonance energy transfer (FRET) mechanism from carbon dots to a naphthalimide fluorophores. The hyaluronidase enzyme cleaves the hyaluronic acid in this assay, and breaking down the FRET mechanism induces ratiometric changes. A detection limit of $0.09 \mathrm{U} / \mathrm{mL}$ was achieved, which is less than the HAase level found in normal human body fluids. Moreover, this assay may be used for diagnosing HAase-related diseases.
\end{abstract}

Keywords: fluorescence; hyaluronic acid; biosensor; hyaluronidase; naphthalimide

\section{Introduction}

Hyaluronic acid (HA) is a linear polysaccharide composed of D-glucuronic acid and $\mathrm{N}$-acetyl-D-glucosamine linked through $\beta(1-3)$ and $\beta(1-4)$ glycosidic bonds $[1,2]$. It is an anionic, non-sulfated glycosaminoglycan produced by the plasma membrane and energetically stable biomolecules [3]. HA is a very important component of the extracellular matrix, and it directly regulates many biological activities, such as cell adhesion, migration, and proliferation [4-6]. Hyaluronidase (HAase) is an enzyme that can cleave the HA into small fragments [7]. Elevated levels of HAase are found in many types of cancer, including bladder cancer, prostate cancer, malignant melanoma, and brain cancer [8-10]. Consequently, it has an important role in clinical diagnosis and early therapy [11]. Bladder cancer is one of the most frequent malignancies and the second highest cause of death in genitourinary cancer patients annually [12,13]. Owing to the high levels of HAase in bladder cancer, HAase has emerged as a new biomarker for the early diagnosis of bladder cancer through the investigation of urinary HAase levels [14,15]. Therefore, it is important to develop a simple and ultrasensitive analytical method for the early detection of HAase. Various methods have been reported for the detection of HAase, such as turbidimetry, viscosimetry, colorimetry, and zymography [16-20]. However, these classical analytical methods have many shortcomings, such as specificity, sensitivity, time-consuming sample preparation, and inaccurate detection results. Immunoassays are another sensitive and specific analytical approach for the detection of HAase [21]. However, they require expensive antibodies and very tedious conjugation and washing steps, which restrict their wide applicability. Recently, fluorescence methods have gained considerable attention for biomolecule detection, owing to their high stability, sensitivity, and feasibility for quantification [22-25]. Based on the donor-acceptor design, numerous fluorescence 
molecular probes, quantum dots, and gold nanoparticles (AuNPs) have been synthesized for hyaluronidase monitoring [26,27]. HAase detection was achieved by the cleavage of the HA assembly, which leads to emission recovery; this was labeled with quantum dots, fluorescent dyes, gold nanoparticles, and up-conversion fluorescent nanoparticles (UCNP) [28-30]. These fluorescence probes have many limitations, such as the blue emission of carbon dots, which can be easily affected by background noise, the aggregation of AuNPs in high-salt biological media, tedious synthetic procedures, multiple non-specific adsorption interactions of molecular probes, and the covalent modification of HA, which are time-consuming and affect the specificity of the sensing probes. Additionally, most of the fluorescence sensors reported for HAase detection are single-wavelength emission, which is easily fluctuated by the external environment, such as temperature, external light, and concentration, thereby inducing false positive results. Yang et al. developed electrostatically-controlled ratiometric fluorescence probes for HAase monitoring [4]. The electrostatic interaction between positively charged fluorescent components (carbon dot as a donor and organic dye as an acceptor) and negatively charged HA develops a Förster resonance energy transfer (FRET) pair assay that exhibits a ratiometric response. Upon the enzymatic hydrolysis of HA, the FRET pair breakdown and ratiometric emission intensity diminish. Based on the same mechanism, fluorescein isothiocyanate (donor) and AuNPs (acceptor) were encapsulated in HA hydrogel [31]. A fluorescence signal was generated in the presence of HAase. Furthermore, Ma et al. developed a perylene (PDI)-based self-assembly for HAase detection [3]. The electrostatic interactions between negatively charged HA and positively charged perylene lead to aggregation-caused quenching. The enzymatic hydrolysis of HA leads to a disruption of the aggregation phenomenon and the recovery of the fluorescence intensity of pure PDI. These fluorescent probes exhibit appropriate simplicity and sensitivity for HAase recognition. However, molecular probes with higher stability and sensitivity are still required for the early diagnosis of cancer. Thus, the development of new fluorescence probes with high sensitivity, selectivity, and stability is of interest for biosensing applications [32]. Herein, we report a simple enzymatic fluorescence assay of negatively charged HA, super-cationic carbon dots, and positively charged naphthalimide fluorophores for HAase detection. Naphthalimide fluorophores are used, owing to their excellent quantum yield, easy synthesis, biocompatibility, water solubility, and tunable electronic properties [33-35]. Similarly, carbon dots are selected owing to their easy and low-cost synthesis, tunable fluorescence, and biocompatibility [36-38]. The overlap of the absorption and emission spectra of naphthalimide and carbon dots leads to the development of a FRET mechanism between both fluorophores. This FRET mechanism was controlled by HA and the HAase, which used for hyaluronidase monitoring. The advantage of this assay is that it is simple, highly sensitive, economically viable, and less time-consuming. Moreover, it shows a ratiometric response that is not altered by external factors, such as temperature, concentration, and external light.

\section{Material and Methods}

\subsection{Chemicals and Reagents}

All chemicals used in this study were of analytical grade. They were purchased from Sigma Aldrich Inc. (Merck KGaA, Darmstadt, Germany) and Alfa Aeser (Thermo Fisher Scientific Inc., Waltham, MA, USA) and used without further purification. The 4aminonaphthalic-anhydride, phosphate buffered saline (PBS) buffer, hyaluronidase, bovine serum albumin (BSA), alkaline phosphatase (ALP), human serum albumin (HSA), glutathione (GSH), glucose, and cysteamine (Cys) were purchased from Sigma Aldrich Inc., and the HA was purchased from Acros Organics (Thermo Fisher Scientific Inc., Waltham, MA, USA). The methyliodide, 3-(dimethylamino)-1-propylamine, ethanol, methanol, spermidine trihydrochloride, $\mathrm{CaCl}_{2}, \mathrm{NaCl}, \mathrm{KCl}, \mathrm{MgCl}_{2}, \mathrm{Zn}\left(\mathrm{NO}_{3}\right)_{2}$, and $\mathrm{Cu}\left(\mathrm{NO}_{3}\right)_{2}$ were purchased from Alfa Aeser. 


\subsection{Instrumentation}

${ }^{1} \mathrm{H}$ nuclear magnetic resonance (NMR) and ${ }^{13} \mathrm{C}$ NMR spectra were recorded on a $600 \mathrm{MHz}$ NMR spectrometer (AVANCE III HD; Bruker Corp., Billerica, MA, USA). The chemical shift values were measured in ppm with respect to tetramethylsilane as an internal standard. The NMR spectra of the compounds were analyzed using TopSpin 4.0.8 software. The ultraviolet (UV)-visible absorption spectra were measured on a UV-visible absorption spectrophotometer (S-3100; Scinco Inc., Seoul, Korea). The samples were recorded in the absorption range of $200-900 \mathrm{~nm}$ in $10 \mathrm{~mm} \times 10 \mathrm{~mm}$ quartz cuvettes. Fluorescence spectra were measured using a fluorescence spectrophotometer (Fluorolog3 with TCSPC; Horiba Ltd., Kyoto, Japan). The emission range of the sample was recorded from 200$900 \mathrm{~nm}$ with a fixed slit width $(5 \mathrm{~mm})$ in a $10 \mathrm{~mm} \times 10 \mathrm{~mm}$ transparent cuvette. The zeta potential of the sample was recorded on a Zetasizer Nano ZS90 (Malvern Panalytical Ltd., Malvern, UK) with folded capillary zeta cell (DTS1070; Malvern Panalytical Ltd., Malvern, United Kingdom). Transmission electron microscopy (TEM) images were obtained using a transmission electron microscope (FEI Tecnai ${ }^{\mathrm{TM}} \mathrm{G}^{2}$ F20; FEI Company, Hillsboro, OR, USA). The samples were deposited on a carbon-coated $\mathrm{Cu}$ grid and observed using a transmission electron microscope operated at $300 \mathrm{kV}$. The Fourier transform infrared (FT-IR) spectra of the carbon dots were measured using an Alpha-P instrument (Bruker Corp.; Billerica, MA, USA).

\subsection{Synthesis of Naphthalimide Probe 1}

\subsubsection{Compound (a)}

Compound (a) was synthesized using a condensation reaction between 4-aminonaphthalic anhydride (198 mg, $1 \mathrm{mmol}$ ) and 3-(dimethylamino)-1-propylamine (102 mg, $1 \mathrm{mmol}$ ) in $10 \mathrm{~mL}$ ethanol and refluxing for $6 \mathrm{~h}$. Subsequently, the reaction mixture was cooled to $24^{\circ} \mathrm{C}$ and a yellowish orange precipitate was separated. The crude product was washed with ethanol and then air-dried. Yield: $80 \% .{ }^{1} \mathrm{H}$ NMR in DMSO- $\mathrm{d}_{6}(\delta=\mathrm{ppm}): 8.67(\mathrm{~d}, 1 \mathrm{H}), 8.50$ $(\mathrm{d}, 1 \mathrm{H}), 8.2(\mathrm{~d}, 1 \mathrm{H}), 7.8(\mathrm{t}, 1 \mathrm{H}), 7.5(\mathrm{~s}, 2 \mathrm{H}), 6.89(\mathrm{~d}, 1 \mathrm{H}), 4.02(\mathrm{t}, 2 \mathrm{H}), 2.3(\mathrm{t}, 2 \mathrm{H}), 2.02(\mathrm{~s}, 6 \mathrm{H})$, and $1.7(\mathrm{t}, 2 \mathrm{H}) .{ }^{13} \mathrm{C}$ NMR in DMSO-d $\mathrm{d}_{6}(\delta=\mathrm{ppm}): 164.2,163.3,134.3,131.4,130.1,129.7$, $124.4,119.8,108.6,108.0,57.3,45.5,26.3$, and 19.0.

\subsubsection{Probe 1}

The naphthalimide probe was synthesized by the nucleophilic substitution reaction of compound (a) (297 mg, $1 \mathrm{mmol}$ ) with methyliodide ( $216 \mathrm{mg}, 1.5 \mathrm{mmol})$ in methanol $(5 \mathrm{~mL})$, and it required stirring for $7 \mathrm{~h}$. After $7 \mathrm{~h}$, the yellow-colored water-soluble precipitate was separated, washed with methanol, and dried in air. Yield: $78 \%,{ }^{1} \mathrm{H}$ NMR in DMSO- $\mathrm{d}_{6}$ $(\delta=\mathrm{ppm}): 8.63(\mathrm{~d}, 1 \mathrm{H}), 8.44(\mathrm{~d}, 1 \mathrm{H}), 8.20(\mathrm{~d}, 1 \mathrm{H}), 7.67(\mathrm{t}, 1 \mathrm{H}), 7.49(\mathrm{~s}, 2 \mathrm{H}), 6.85(\mathrm{~d}, 1 \mathrm{H})$, $4.09(\mathrm{t}, 2 \mathrm{H}), 3.32(\mathrm{t}, 2 \mathrm{H}), 3.02(\mathrm{~s}, 9 \mathrm{H})$, and $2.09(\mathrm{t}, 2 \mathrm{H}),{ }^{13} \mathrm{C} \mathrm{NMR}$ in DMSO-d $\mathrm{d}_{6}(\delta=\mathrm{ppm})$ : $164.5,163.5,153.3,134.5,131.5,130.3,129.9,124.4,122.2$, 119.8, 108.6, 107.9, 63.8, 52.6, 36.8, and 22.3 .

\subsection{Synthesis of Cationic Carbon Dots (CQDs)}

Carbon dots were synthesized using a previously reported method [39]. Briefly, $100 \mathrm{mg}$ of spermidine trihydrochloride was kept at $240{ }^{\circ} \mathrm{C}$ for $3 \mathrm{~h}$. A dark black solid was dissolved in deionized (DI) water. The carbon dot solution was centrifuged at a relative centrifugal force of $20,000 \times g$ for $1 \mathrm{~h}$. The resulting solid pellet was removed, and the supernatant was dialyzed against DI water through a dialysis membrane (molecular weight cut-off $=1.0 \mathrm{kDa}$ ) and vacuum-dried at $60^{\circ} \mathrm{C}$. The purified solution was stored at $4{ }^{\circ} \mathrm{C}$.

\subsection{Detection of HAase}

In the control experiment, $50 \mu \mathrm{L}(50 \mu \mathrm{g} / \mathrm{mL})$ of the carbon dots, $50 \mu \mathrm{L}(20 \mu \mathrm{g} / \mathrm{mL})$ of $\mathrm{HA}, 5 \mu \mathrm{M}$ of naphthalimide, and $20 \mathrm{U} / \mathrm{mL}$ of HAase were used in a PBS buffer at $\mathrm{pH} 7.4$ for HAase detection. The resulting solution was incubated at $37^{\circ} \mathrm{C}$ for a specific period 
of time (0-60 $\mathrm{min})$, and fluorescence spectra were recorded for the quantitative analysis of HAase.

\section{Result and Discussions}

\subsection{Synthesis and Characterization of Carbon Dots}

Cationic carbon dots were synthesized by the hydrothermal reaction of spermidine trihydrochloride and characterized by UV-visible absorption, emission, and TEM analysis. The UV-visible absorption spectra of the carbon dots show absorption bands $\left(\lambda_{\mathrm{abs}}\right)$ at $270 \mathrm{~nm}$, corresponding to the $\pi-\pi^{*}$ transition of the $\mathrm{C}=\mathrm{C}$ bond, while a shoulder band at $300-450 \mathrm{~nm}$ corresponds to the $\mathrm{n}-\pi^{*}$ transition of the $\mathrm{C}=\mathrm{O}$ and $\mathrm{C}=\mathrm{N}$ bonds, as shown in Figure 1A [40]. The excitation-dependent emission confirms the formation of carbon dots and is attributed to polycyclic clusters of different sizes, surface defects, and particles of different sizes, as shown in Figure 1B [41]. The TEM image studies show that the particles are spherical in shape and have sizes of 6-8 nm (Figure S1). The FT-IR spectra of the carbon exhibited vibration bands at 3200-3400, 2220-2260, and $1125 \mathrm{~cm}^{-1}$, corresponding to the $\mathrm{N}-\mathrm{H}, \mathrm{C} \equiv \mathrm{N}$, and $\mathrm{C}-\mathrm{N}$ stretching vibrations, respectively. $\mathrm{N}-\mathrm{H}$ bending was observed at $1600-1620 \mathrm{~cm}^{-1}$, as shown in Figure 1C. Thus, the FT-IR results clearly demonstrate that the carbon dots have a polyamine-like structure. It is well documented in the previous literature that carbon dots derived from quaternized ammonium surface precursors are positively charged or cationic in nature [42,43]. Hence, this assumption for positively charged carbon dots was confirmed by measuring the zeta potential of the synthesized

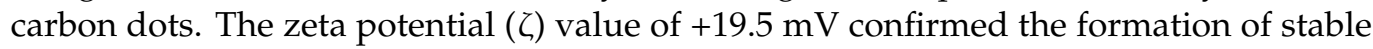
cationic carbon dots (Figure S2).
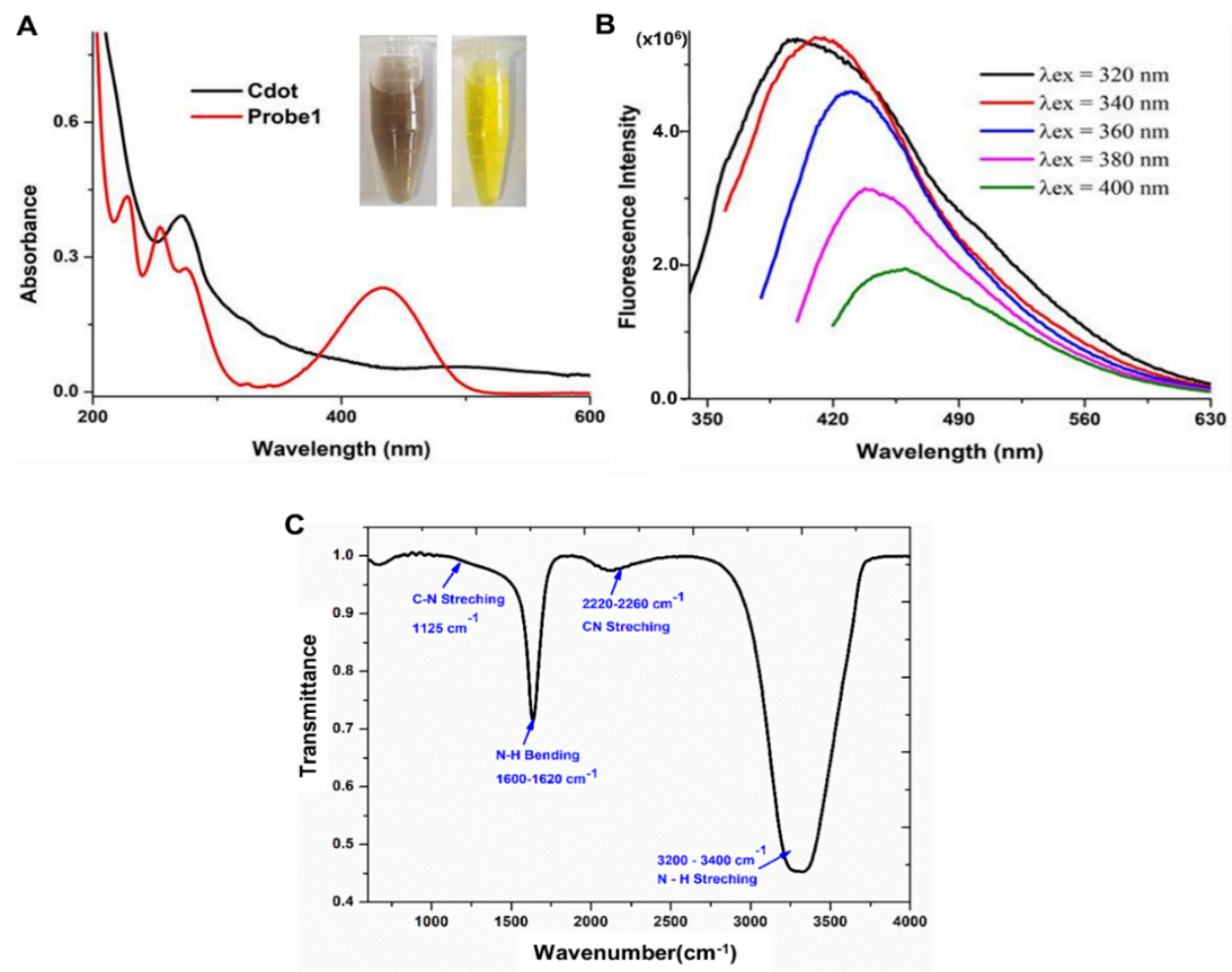

Figure 1. (A): UV-visible absorption spectra of carbon dots and probe $1(10 \mu \mathrm{M})$ in an aqueous medium. (B): Excitationdependent emission spectra of carbon dots in aqueous medium. (C): FTIR spectra of carbon dots

\subsection{Synthesis of Naphthalimide Probe 1}

Naphthalimide probe 1 was synthesized by a two-step reaction, that is, condensation followed by a nucleophilic substitution reaction (Scheme 1). The final product was 
characterized using NMR spectroscopy (Figures S3-S6). The NMR signal at $3.03 \mathrm{ppm}$, attributed to the $9 \mathrm{H}$ proton of the trimethyl group, confirms the formation of probe 1 . The UV-visible absorption spectra of probe $1(10 \mu \mathrm{M})$ in an aqueous medium exhibited prominent absorption peaks ( $\left.\lambda_{\text {abs }}\right)$ at 430 and $280 \mathrm{~nm}$, which are assigned to the $\pi-\pi^{*}$ and $\mathrm{n}-\pi^{*}$ transitions of the ligand, respectively, as shown in Figure 1A [44]. Probe 1 was excited $\left(\lambda_{\mathrm{ex}}\right)$ at $430 \mathrm{~nm}$ and emitted $\left(\lambda_{\mathrm{em}}\right)$ at $542 \mathrm{~nm}$, as shown in Figure S7.

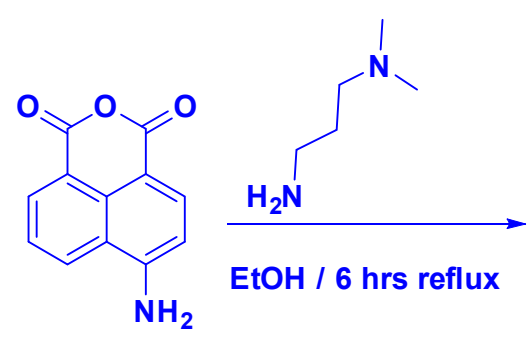

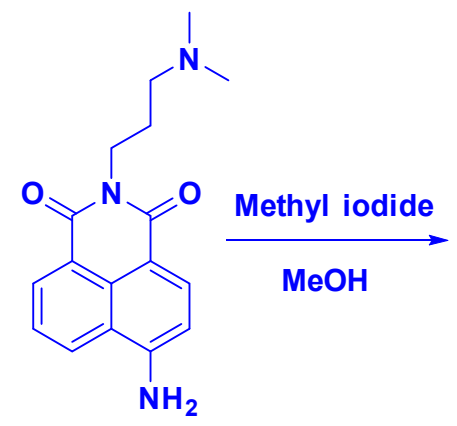

(a)<smiles>C[N+](C)(CI)CCCN1C(=O)c2cccc3c(N)ccc(c23)C1=O</smiles>

(1)

Scheme 1. Synthesis of naphthalimide-based fluorescence probe 1.

\subsection{Sensing Mechanism}

Two emission wavelength-based fluorescence sensors were designed to obtain a FRET mechanisam because the emission spectra of the carbon dots overlapped considerably with the absorption spectra of naphthalimide probe 1, as shown in Figure S8. The cationic carbon dot and naphthalimide probe were adsorbed on negatively charged HA through electrostatic interactions, and they formed a supramolecular nanoassembly. The supramolecular assemblies were characterized by TEM image analysis (Figure 2). The TEM image results show that the supramolecular nanoassembly changed from an aggregate state to a dispersion solution after treatment using HAase. The HAase enzyme selectively hydrolyzes the HA into small fragments and breaks down the supramolecular assemblies, leading to a disruption of the FRET mechanism, as shown in Figure 3.
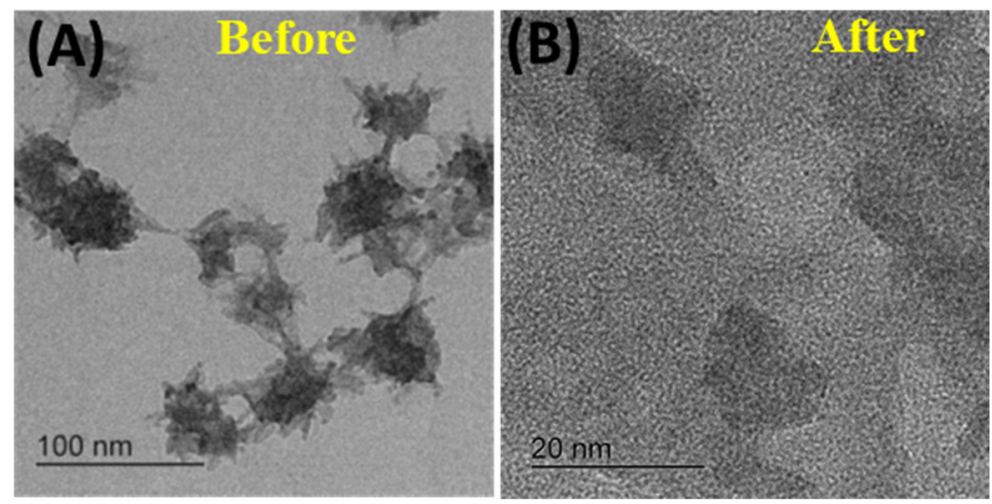

Figure 2. TEM images of sensor system, (A): before HAase addition, (B): after HAase addition $(20 \mathrm{U} / \mathrm{mL})$. 


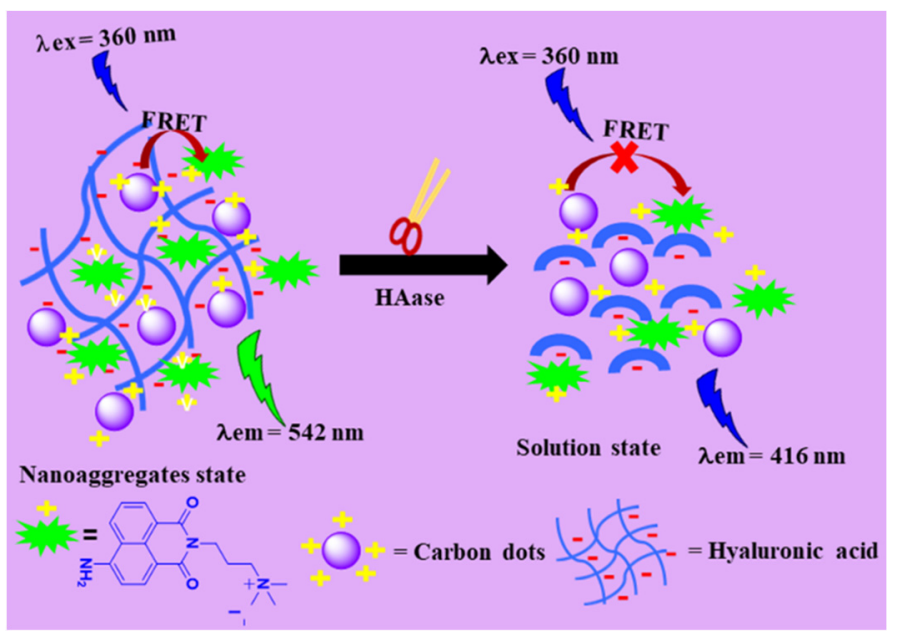

Figure 3. Graphical representation of the FRET mechanism for the sensing of hyaluronidase.

\subsection{Fluorescence Sensing}

\subsubsection{Optimization of Experimental Conditions}

The optimization conditions of the sensor system were significantly affected by changes in $\mathrm{pH}$ and concentration of the fluorophore. Initially, a series of experiments were conducted to fix the concentration of the two fluorophores. Finally, $50 \mu \mathrm{L}$ of carbon dots and $5 \mu \mathrm{M}$ of naphthalimide probe 1 exhibited equal fluorescence intensities at $416 \mathrm{~nm}$ and $542 \mathrm{~nm}$, respectively, indicating a good scope of ratiometric change. Accordingly, this concentration for the sensor was chosen for further studies. The effect of $\mathrm{pH}$ on the sensing probe was measured using fluorescence spectroscopy by changing $\mathrm{pH}$ from 4 to 11 . The fluorescence intensity of the sensor remained unaltered at an acidic $\mathrm{pH}$. Conversely, under basic conditions, the fluorescence intensity changed significantly, as shown in Figure 4 . The fluorescence intensity of the carbon dots remained stable in both acidic and basic media, whereas naphthalimide probe 1 exhibited a decrease in fluorescence intensity with an increase in $\mathrm{pH}$. Therefore, to confirm the stability of the sensor, we implemented all recognition studies in the PBS buffer $(10 \mathrm{mM}, \mathrm{pH}=7.4)$.

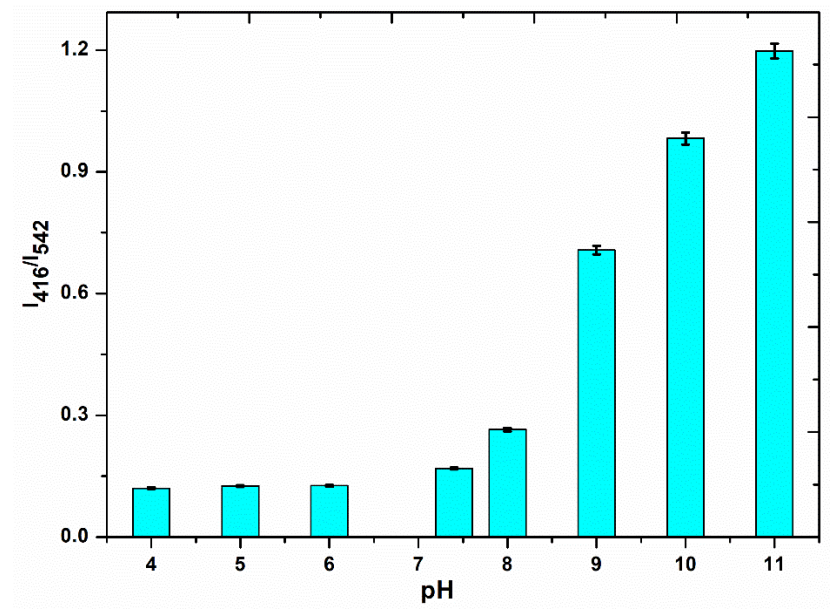

Figure 4. Effect of $\mathrm{pH}$ on the fluorescence intensity of the sensing system.

\subsubsection{Performance of Sensor System}

The sensing ability of the sensor probe $(50 \mu \mathrm{L}$ of carbon dots, $50 \mu \mathrm{L}$ of HA, and $5 \mu \mathrm{M}$ of naphthalimide probe in PBS buffer at $\mathrm{pH}$ 7.4) for HAase detection was measured using fluorescence spectroscopy. The fluorescence spectra of the sensor system were excited at $\lambda_{\mathrm{ex}}=360 \mathrm{~nm}$ and exhibited two emission wavelengths $\left(\lambda_{\mathrm{em}}\right)$ at $416 \mathrm{~nm}$, which was assigned 
to the carbon dots emission, and $542 \mathrm{~nm}$, which was assigned to naphthalimide emission. The two emissions in the sensor system occurred owing to the adsorption of cationic carbon dots and the positively charged naphthalimide probe on the negatively charged HA through electrostatic interactions and the development of a FRET mechanism from the carbon dots to naphthalimide probe 1. Upon the addition of HAase to the sensing probe, the fluorescence intensity at $542 \mathrm{~nm}$ started to decrease, and the fluorescence intensity at $416 \mathrm{~nm}$ increased. This was owing to the hydrolysis of HA by the enzyme HAase, and because the FRET mechanism developed from carbon dots to naphthalimide was inhibited. Furthermore, an incremental quantity of HAase $(0-80 \mathrm{U} / \mathrm{mL})$ was added to the sensor system, and the fluorescence intensity was recorded. The fluorescence titration experiment showed that the sensor system exhibited a ratiometric response to the addition of HAase (Figure 5A). The calibration plot exhibited a linear relationship $\left(R^{2}=0.993\right)$ between the fluorescence intensity and the concentration of HAase (Figure 5B). The kinetics of the enzymatic reaction was investigated by recording the time-dependent fluorescence spectra of the sensor system in the presence of HAase $(20 \mathrm{U} / \mathrm{mL})$. The resulting solution was incubated at $37^{\circ} \mathrm{C}$ for a specific period (0-60 $\mathrm{min}$ ) and fluorescence spectra were then recorded to perform a quantitative analysis of HAase. The fluorescence spectra of the sensor system exhibited an increase in fluorescence intensity at $416 \mathrm{~nm}$ and a decrease at $542 \mathrm{~nm}$ with an increase in time, subsequently reaching a maximum at $60 \mathrm{~min}$ (Figure 5C). Further, to confirm complete enzymatic activity, the enzyme was incubated for $80 \mathrm{~min}$ for the fluorescence experiment. The detection limit was determined by the 3 sigma method. We obtained a value of $0.09 \mathrm{U} / \mathrm{mL}$, which is less than the HAase level $(0.26 \pm 0.20 \mathrm{U} / \mathrm{mL})$ found in normal human serum [45]. To make the proposed fluorescence assay useful in practice, further improvements are still needed; these will require further testing in complex fluid matrixes, such as serum and urine samples. The results should also be compared with thoes of traditional methods. Nevertheless, the above results suggest that the current approach is simple and highly sensitive for the detection of HAase compared with previous approaches reported in the literature (Table S1).
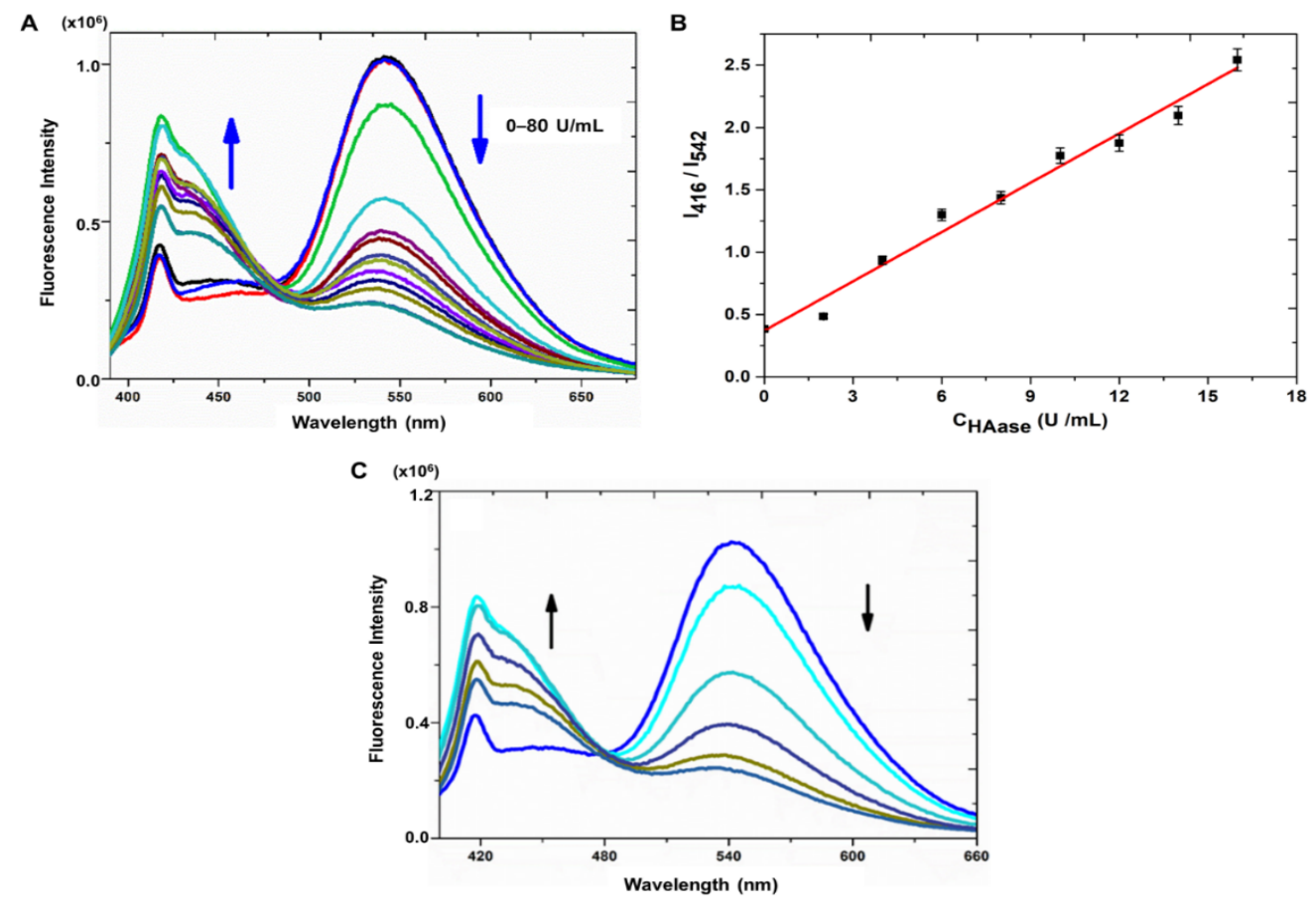

Figure 5. (A): Fluorescence titration experiment for sensor probe with HAase $(0-80 \mathrm{U} / \mathrm{mL})$ in phosphate buffered saline (PBS) buffer $(10 \mathrm{mM}, \mathrm{pH}=7.4)$. (B): Calibration plot between fluorescence intensity at $\mathrm{I}_{416} / \mathrm{I}_{542}$ versus HAase concentration (0.1-16 U/mL). (C): Time-dependent fluorescence spectra of the sensor system in the presence of $20 \mathrm{U} / \mathrm{mL}$ of $\mathrm{HAase}$. 


\subsection{Selectivity Studies}

The selectivity of the sensing probe for HAase detection was determined using potential interfering analytes, such as $\mathrm{Mg}$ (II), Ca (II), Zn (II), Cu (II), Na (I), K (I), BSA, HSA, glucose, Cys, and ALP ( $1 \mathrm{U} / \mathrm{mL})$, under identical experimental conditions. Figure 6 shows that none of these competitive analytes exhibited changes in the fluorescence intensity of the sensing probe. HAase caused a considerable change in the fluorescence intensity $\left(\mathrm{I}_{416} / \mathrm{I}_{542}\right)$ of the sensing probe, confirming the high selectivity of the sensor towards HAase detection.

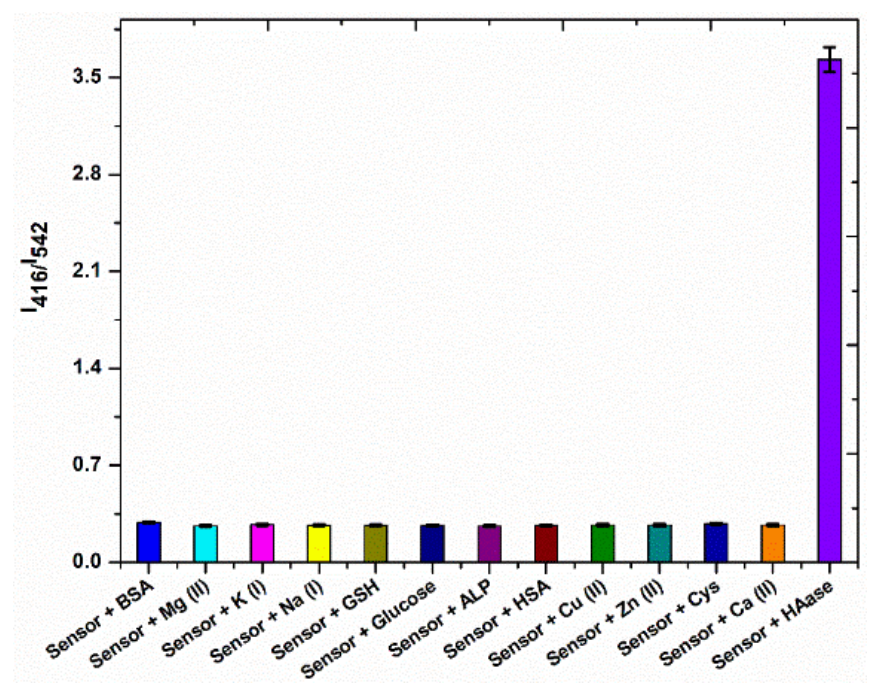

Figure 6. Fluorescence spectra of the sensor system in the presence of different competitive analytes $(50 \mu \mathrm{M})$ in PBS buffer $(10 \mathrm{mM}, \mathrm{pH}=7.4)$.

\section{Conclusions}

We developed a simple, rapid, and sensitive fluorescence assay for the ratiometric detection of HAase in an aqueous medium. The FRET mechanism was successfully used to detect HAase. None of the competitive analytes interfered with the detection of HAase. A low detection limit of $0.09 \mathrm{U} / \mathrm{mL}$ was achieved, which is less than the HAase concentration in normal human serum. Moreover, this bioassay may find potential applications in the clinical diagnosis of HAase-related diseases.

Supplementary Materials: The following are available online at https://www.mdpi.com/1996-1 944/14/5/1313/s1, Figure S1: TEM image of carbon dot. (A) Low resolution TEM image; (B) high resolution TEM image. Figure S2: Zeta potential of carbon dots in $10 \mathrm{mM}$ of PBS at $\mathrm{pH}$ 7.4. Figure S3: ${ }^{1} \mathrm{H}$ NMR spectrum of compound (a) in DMSO- $\mathrm{d}_{6}$. Figure S4: ${ }^{13} \mathrm{C}$ NMR spectrum of compound (a) in DMSO-d $\mathrm{d}_{6}$. Figure S5: ${ }^{1} \mathrm{H}$ NMR spectrum of probe 1 in DMSO- $\mathrm{d}_{6}$ Figure S6: ${ }^{13} \mathrm{C}$ NMR spectrum of probe 1 in DMSO-d $\mathrm{d}_{6}$. Figure S7: Emission spectra of naphthalimide probe $1(10 \mu \mathrm{M})$ in water. Figure S8: Spectral overlap of carbon dot and probe 1. Table S1: Comparison between previous reported studies and the presented sensor

Author Contributions: Conceptualization, T.Y.L.; Methodology, P.R.; Validation, S.-y.L.; WritingOriginal Draft Preparation, P.R.; Writing-Review and Editing, T.Y.L.; Funding Acquisition, T.Y.L. All authors have read and agreed to the published version of the manuscript.

Funding: This research was supported by a research fund from Chungnam National University.

Institutional Review Board Statement: Not applicable.

Informed Consent Statement: Not applicable.

Data Availability Statement: Data available on request to corresponding author.

Conflicts of Interest: The authors declare that there are no conflict of interest. 


\section{References}

1. Lapčík, L.; Lapčík, L.; De Smedt, S.; Demeester, J.; Chabreček, P. Hyaluronan: Preparation, Structure, Properties, and Applications. Chem. Rev. 1998, 98, 2663-2684. [CrossRef] [PubMed]

2. Huang, Y.; Song, C.; Li, H.; Zhang, R.; Jiang, R.; Liu, X.; Zhang, G.; Fan, Q.; Wang, L.; Huang, W. Cationic Conjugated Polymer/Hyaluronan-Doxorubicin Complex for Sensitive Fluorescence Detection of Hyaluronidase and Tumor-Targeting Drug Delivery and Imaging. ACS Appl. Mater. Interfaces 2015, 7, 21529-21537. [CrossRef] [PubMed]

3. Ma, L.; Gao, W.; Han, X.; Qu, F.; Xia, L.; Kong, R.-M. A label-free and fluorescence turn-on assay for sensitive detection of hyaluronidase based on hyaluronan-induced perylene self-assembly. New J. Chem. 2019, 43, 3383-3389. [CrossRef]

4. Yang, W.; Ni, J.; Luo, F.; Weng, W.; Wei, Q.; Lin, Z.; Chen, G. Cationic carbon dots for modification-free detection of hyaluronidase via an electrostatic-controlled ratiometric fluorescence assay. Anal. Chem. 2017, 89, 8384-8390. [CrossRef] [PubMed]

5. Turley, E.A.; Noble, P.W.; Bourguignon, L.Y.W. Signaling properties of hyaluronan receptors. J. Biol. Chem. 2002, 277 , 4589-4592. [CrossRef]

6. Lokeshwar, V.B.; Selzer, M.G. Hyaluronidase: Both a tumor promoter and suppressor. In Hyaluronan in Cancer Biology; Elsevier: Amsterdam, The Netherlands, 2009; pp. 189-206.

7. Whatcott, C.J.; Han, H.; Posner, R.G.; Hostetter, G.; Von Hoff, D.D. Targeting the tumor microenvironment in cancer: Why hyaluronidase deserves a second look. Cancer Discov. 2011, 1, 291-296. [CrossRef]

8. Lokeshwar, V.B.; Rubinowicz, D.; Schroeder, G.L.; Forgacs, E.; Minna, J.D.; Block, N.L.; Nadji, M.; Lokeshwar, B.L. Stromal and epithelial expression of tumor markers hyaluronic acid and HYAL1 hyaluronidase in prostate cancer. J. Biol. Chem. 2001, 276, 11922-11932. [CrossRef]

9. Tan, J.; Wang, X.; Li, H.; Su, X.; Wang, L.; Ran, L.; Zheng, K.; Ren, G. HYAL1 overexpression is correlated with the malignant behavior of human breast cancer. Int. J. Cancer 2011, 128, 1303-1315. [CrossRef]

10. Martinez-Quintanilla, J.; He, D.; Wakimoto, H.; Alemany, R.; Shah, K. Encapsulated stem cells loaded with hyaluronidaseexpressing oncolytic virus for brain tumor therapy. Mol. Ther. 2015, 23, 108-118. [CrossRef]

11. Yang, K.; Liu, M.; Wang, Y.; Wang, S.; Miao, H.; Yang, L.; Yang, X. Carbon dots derived from fungus for sensing hyaluronic acid and hyaluronidase. Sens. Actuators B Chem. 2017, 251, 503-508. [CrossRef]

12. Eissa, S.; Kassim, S.K.; Labib, R.A.; El-Khouly, I.M.; Ghaffer, T.M.; Sadek, M.; Razek, O.A.; El-Ahmady, O. Detection of bladder carcinoma by combined testing of urine for hyaluronidase and cytokeratin 20 RNAs. Cancer 2005, 103, 1356-1362. [CrossRef] [PubMed]

13. Thompson, C.B.; Shepard, H.M.; O'Connor, P.M.; Kadhim, S.; Jiang, P.; Osgood, R.J.; Bookbinder, L.H.; Li, X.; Sugarman, B.J.; Connor, R.J. Enzymatic depletion of tumor hyaluronan induces antitumor responses in preclinical animal models. Mol. Cancer Ther. 2010, 9, 3052-3064. [CrossRef] [PubMed]

14. Liu, Q.; Yan, X.; Lai, Q.; Su, X. Bimetallic gold/silver nanoclusters-gold nanoparticles based fluorescent sensing platform via the inner filter effect for hyaluronidase activity detection. Sens. Actuators B Chem. 2019, 282, 45-51. [CrossRef]

15. Hu, P.; Chen, Y.; Liu, Y. Hyaluronan/Ru(ii)-cyclodextrin supramolecular assemblies for colorimetric sensor of hyaluronidase activity. RSC Adv. 2015, 5, 99240-99244. [CrossRef]

16. Magalhães, M.R.; da Silva, N.J., Jr.; Ulhoa, C.J. A hyaluronidase from Potamotrygon motoro (freshwater stingrays) venom: Isolation and characterization. Toxicon 2008, 51, 1060-1067. [CrossRef]

17. Vercruysse, K.P.; Lauwers, A.R.; Demeester, J.M. Absolute and empirical determination of the enzymatic activity and kinetic investigation of the action of hyaluronidase on hyaluronan using viscosimetry. Biochem. J. 1995, 306, 153-160. [CrossRef]

18. Kim, J.-W.; Kim, J.H.; Chung, S.J.; Chung, B.H. An operationally simple colorimetric assay of hyaluronidase activity using cationic gold nanoparticles. Analyst 2009, 134, 1291-1293. [CrossRef]

19. Nossier, A.I.; Eissa, S.; Ismail, M.F.; Hamdy, M.A.; Azzazy, H.M.E.-S. Direct detection of hyaluronidase in urine using cationic gold nanoparticles: A potential diagnostic test for bladder cancer. Biosens. Bioelectron. 2014, 54, 7-14. [CrossRef]

20. Steiner, B.; Cruce, D. A zymographic assay for detection of hyaluronidase activity on polyacrylamide gels and its application to enzymatic activity found in bacteria. Anal. Biochem. 1992, 200, 405-410. [CrossRef]

21. Jayadev, C.; Rout, R.; Price, A.; Hulley, P.; Mahoney, D. Hyaluronidase treatment of synovial fluid to improve assay precision for biomarker research using multiplex immunoassay platforms. J. Immunol. Methods 2012, 386, 22-30. [CrossRef]

22. Ai, H. Fluorescent sensors for biological applications. Sensors 2014, 14, 17829-17831. [CrossRef]

23. Li, X.; Wu, T.; Fu, Y.; Ding, X.; Li, Z.; Zhu, G.; Fan, J. A high sensitivity background eliminated fluorescence sensing platform for hyaluronidase activity detection based on Si QDs/HA- $\delta$-FeOOH nanoassembly. Biosens. Bioelectron. 2020, 150, 111928. [CrossRef]

24. Gao, N.; Yang, W.; Nie, H.; Gong, Y.; Jing, J.; Gao, L.; Zhang, X. Turn-on theranostic fluorescent nanoprobe by electrostatic self-assembly of carbon dots with doxorubicin for targeted cancer cell imaging, in vivo hyaluronidase analysis, and targeted drug delivery. Biosens. Bioelectron. 2017, 96, 300-307. [CrossRef]

25. Panagiotopoulou, M.; Kunath, S.; Medina-Rangel, P.X.; Haupt, K.; Tse Sum Bui, B. Fluorescent molecularly imprinted polymers as plastic antibodies for selective labeling and imaging of hyaluronan and sialic acid on fixed and living cells. Biosens. Bioelectron. 2017, 88, 85-93. [CrossRef]

26. Hu, Q.; Zeng, F.; Wu, S. A ratiometric fluorescent probe for hyaluronidase detection via hyaluronan-induced formation of red-light emitting excimers. Biosens. Bioelectron. 2016, 79, 776-783. [CrossRef] 
27. Gu, W.; Yan, Y.; Zhang, C.; Ding, C.; Xian, Y. One-Step Synthesis of Water-Soluble MoS2 Quantum Dots via a Hydrothermal Method as a Fluorescent Probe for Hyaluronidase Detection. ACS Appl. Mater. Interfaces 2016, 8, 11272-11279. [CrossRef] [PubMed]

28. Xie, H.; Zeng, F.; Wu, S. Ratiometric Fluorescent Biosensor for Hyaluronidase with Hyaluronan As Both Nanoparticle Scaffold and Substrate for Enzymatic Reaction. Biomacromolecules 2014, 15, 3383-3389. [CrossRef]

29. Wang, Z.; Li, X.; Song, Y.; Li, L.; Shi, W.; Ma, H. An Upconversion Luminescence Nanoprobe for the Ultrasensitive Detection of Hyaluronidase. Anal. Chem. 2015, 87, 5816-5823. [CrossRef] [PubMed]

30. Ge, J.; Cai, R.; Yang, L.; Zhang, L.; Jiang, Y.; Yang, Y.; Cui, C.; Wan, S.; Chu, X.; Tan, W. Core-Shell HA-AuNPs@SiNPs Nanoprobe for Sensitive Fluorescence Hyaluronidase Detection and Cell Imaging. ACS Sustain. Chem. Eng. 2018, 6, 16555-16562. [CrossRef]

31. Ge, M.; Sun, J.; Chen, M.; Tian, J.; Yin, H.; Yin, J. A hyaluronic acid fluorescent hydrogel based on fluorescence resonance energy transfer for sensitive detection of hyaluronidase. Anal. Bioanal. Chem. 2020, 412, 1915-1923. [CrossRef] [PubMed]

32. Liu, W.; Ding, F.; Wang, Y.; Lu, Z.; Zou, P.; Wang, X.; Zhao, Q.; Rao, H. A dual-readout nanosensor based on biomass-based C-dots and chitosan@AuNPs with hyaluronic acid for determination of hyaluronidase. Luminescence 2020, 35, 43-51. [CrossRef] [PubMed]

33. Banerjee, S.; Veale, E.B.; Phelan, C.M.; Murphy, S.A.; Tocci, G.M.; Gillespie, L.J.; Frimannsson, D.O.; Kelly, J.M.; Gunnlaugsson, T. Recent advances in the development of 1,8-naphthalimide based DNA targeting binders, anticancer and fluorescent cellular imaging agents. Chem. Soc. Rev. 2013, 42, 1601-1618. [CrossRef] [PubMed]

34. Duke, R.M.; Veale, E.B.; Pfeffer, F.M.; Kruger, P.E.; Gunnlaugsson, T. Colorimetric and fluorescent anion sensors: An overview of recent developments in the use of 1,8-naphthalimide-based chemosensors. Chem. Soc. Rev. 2010, 39, 3936-3953. [CrossRef] [PubMed]

35. Meher, N.; Iyer, P.K. Functional group engineering in naphthalimides: A conceptual insight to fine-tune the supramolecular self-assembly and condensed state luminescence. Nanoscale 2019, 11, 13233-13242. [CrossRef]

36. Lim, S.Y.; Shen, W.; Gao, Z. Carbon quantum dots and their applications. Chem. Soc. Rev. 2015, 44, 362-381. [CrossRef]

37. Liu, M.L.; Chen, B.B.; Li, C.M.; Huang, C.Z. Carbon dots: Synthesis, formation mechanism, fluorescence origin and sensing applications. Green Chem. 2019, 21, 449-471. [CrossRef]

38. Wang, X.; Feng, Y.; Dong, P.; Huang, J. A Mini Review on Carbon Quantum Dots: Preparation, Properties, and Electrocatalytic Application. Front. Chem. 2019, 7, 671. [CrossRef]

39. Jian, H.-J.; Wu, R.-S.; Lin, T.-Y.; Li, Y.-J.; Lin, H.-J.; Harroun, S.G.; Lai, J.-Y.; Huang, C.-C. Super-Cationic Carbon Quantum Dots Synthesized from Spermidine as an Eye Drop Formulation for Topical Treatment of Bacterial Keratitis. ACS Nano 2017, 11, 6703-6716. [CrossRef]

40. Wang, S.; Cole, I.S.; Zhao, D.; Li, Q. The dual roles of functional groups in the photoluminescence of graphene quantum dots. Nanoscale 2016, 8, 7449-7458. [CrossRef]

41. Gan, Z.; Xu, H.; Hao, Y. Mechanism for excitation-dependent photoluminescence from graphene quantum dots and other graphene oxide derivates: Consensus, debates and challenges. Nanoscale 2016, 8, 7794-7807. [CrossRef]

42. Maiti, S.; Das, K.; Das, P.K. Label-free fluorimetric detection of histone using quaternized carbon dot-DNA nanobiohybrid. Chem. Commun. 2013, 49, 8851-8853. [CrossRef] [PubMed]

43. Liu, W.; Li, C.; Ren, Y.; Sun, X.; Pan, W.; Li, Y.; Wang, J.; Wang, W. Carbon dots: Surface engineering and applications. J. Mater. Chem. B 2016, 4, 5772-5788. [CrossRef] [PubMed]

44. Wang, L.; Fujii, M.; Yamaji, M.; Okamoto, H. Fluorescence behaviour of 2-, 3- and 4-amino-1,8-naphthalimides: Effects of the substitution positions of the amino functionality on the photophysical properties. Photochem. Photobiol. Sci. 2018, 17, 1319-1328. [CrossRef] [PubMed]

45. Marei, W.F.A.; Salavati, M.; Fouladi-Nashta, A.A. Critical role of hyaluronidase-2 during preimplantation embryo development. Mol. Hum. Reprod. 2013, 19, 590-599. [CrossRef] 